\title{
Real-time ed end-point Polymerase Chain Reaction per la quantizzazione del DNA di Citomegalovirus: confronto tra metodi e con il test per l'antigene pp65
}

\author{
Tiziano Allice, Marco Enrietto, Fabrizia Pittaluga, Silvia Varetto, Teresa Zaccaria, \\ Giovanna Marchiaro, Valeria Ghisetti
}

S.C. Microbiologia, Ospedale Molinette, Azienda Ospedaliera San Giovanni Battista di Torino

Key words: CMV, real-time PCR, end-point PCR, Liver Transplantation

Quantitation of Cytomegalovirus DNA by Real-Time Polymerase Chain Reaction in peripheral blood specimens of solid organ transplanted patients: comparison with End-Point PCR and Pp65 antigen test

\section{SUMMARY}

Quantitave Polymerase Chain Reaction (PCR) for Cytomegalovirus (CMV) DNA provides highly sensitive and specific data for detecting CMV as well as monitoring the infection and determining the appropriate antiviral strategy. To determine the clinical application of a recently introduced real-time (RT) PCR assay for CMV DNA quantitation in peripheral blood leukocytes (PBLs) and defining its correlation with the commercial quantitative end-point (EP) PCR method COBAS AMPLICOR CMV Monitor and Pp65 antigen test. Sequential PBL samples $(n=158)$ from 32 liver transplanted patients with CMV asymptomatic infection and positive for CMV DNA by EP-PCR were retrospectively analysed with RT-PCR and studied according to PP65 antigen levels. A good correlation was found between RT-PCR and Pp65 antigen test $(r=0.69 \mathrm{I})$ and between the two PCR assays $(r=0.76 \mathrm{I})$. RT-PCR data were significantly higher in pre-emptive treated patients (those with $>20$ pp $65+$ positive cells, median value: $3.8 \log _{10}$ copies/500,000 PBLs) than in not-treated ones (2.9 logs). According to pp65 levels of $0,1-10$, I I-20, 2 I-50, $5 \mathrm{I}-100$ and > 100 positive cells/200,000 PBLs, median CMV DNA load by RT-PCR was 2.6, 3.0, 3.6, 4.0. 4.2 and 4.8, $\log _{10}$ copies/ 500,000 PBLs, respectively (EP-PCR CMV DNA levels: 2. 8, 2.9, 3.8, 3.7, 3.9 and 4.0 logs). For samples with $>20$ pp $65+$ cells, that is above the level at which pre-emptive therapy was started, RT-PCR values were significantly higher than in groups with less than 20 pP65+cells, whereas EP-PCR values did not significantly differ and showed a slower progression rate. Dilutions of DNA from CMV ADI69 strain were used to probe RT-PCR reproducibility (between and intra-assay variability $<2 \%)$ and sensitivity $(100 \%$ detection rate at 10 copies/reaction, $28.5 \%$ with EP-PCR). A significant improvement is coming from the introduction of RT-PCR to the study of CMV DNA dynamics in differently CMV infected patients due to a more reliable quantitation of CMV DNA for moderate and high DNA level compared to EP-PCR with better sensitivity and specificity. RT$P C R$ gives more precise informations on viral load kinetics for evaluating the infection progress and assessing antiviral response, significantly simplifying and accelerating the process of producing a reliable quantification of CMV DNA for clinical purposes.

\section{INTRODUZIONE}

L'infezione da Citomegalovirus (CMV) nei pazienti trapiantati d'organo solido e di midollo osseo è un'importante causa di morbilità, nonostante la disponibilità di terapia e diagnosi precoci d'infezione (17). L'efficacia della terapia precoce dipende dall'utilizzo di accurati test di laboratorio che rilevano la presenza del CMV nei primi stadi dell'infezione. Molte sono le tecniche utilizzate per identificare CMV e i suoi marcatori precoci di infezione (3). I test molecolari per lo studio quantitativo della dinamica di CMV forniscono dati altamente sensibili e specifici che permettono di individuare i soggetti ad alto rischio di sviluppare la malattia sistemica o d'organo e di personalizzare la terapia antivirale (28).

I metodi tradizionali di identificazione di CMV basati sull'isolamento virale o sull'identificazione rapida in colture cellulari, sono moderatamente sensibili e danno risultati in tempi lunghi. La ricerca della fosfoproteina virale di matrice pp65 (test dell'antigene pp65 o antigenemia) nei leucociti del sangue periferico (PBL), è una tecnica altamente specifica e sensibile per l'identificazione precoce dell'infezione da CMV ed è perciò ampiamente utilizzata come "gold standard" per la diagnosi e il monitoraggio dell'infezione nei pazienti immunosoppressi. Tuttavia, il test del- 
l'antigene pp65 è un metodo completamente manuale, richiede l'immediato processamento dei campioni e una buona esperienza per la corretta interpretazione del risultato; risulta perciò difficilmente standardizzabile ed è stata osservata una significativa variabilità interlaboratorio in termini di sensibilità (da 50 a $83 \%$ ) e di specificità (meno di $80 \%)(4,10,11,28)$. Inoltre, il test è di difficile utilizzo in routine costituite da un numero elevato di campioni. La presenza del DNA virale (CMV DNA) può essere valutata con la polymerase chain reaction (PCR), tecnica più sensibile del test dell'antigene pp65 ma che nel formato qualitativo ha scarse applicazioni cliniche in quanto non consente di discriminare tra infezione latente e produttiva (15). La PCR quantitativa, invece, permette di valutare la carica virale, il cui andamento correla con l'evoluzione dell'infezione, come osservato in molti lavori $(2,4,10,17$, $23,24,26,31)$. Lo studio dell'evoluzione dell'infezione da CMV durante il follow-up dei riceventi, definendo il cut off di riferimento mediante la quantizzazione di CMV DNA in PCR, è una promettente via per identificare i pazienti che presentano un elevato rischio di sviluppare la malattia e ottimizzare il trattamento precoce $(7,13,24,28)$. La quantizzazione mediante PCR può essere realizzata con due approcci differenti: l'end-point e la real-time PCR, tecniche entrambe disponibili commercialmente per l'analisi del CMV. L'EndPoint PCR (EP-PCR) necessita della fase post$\mathrm{PCR}$, è perciò laboriosa e lunga e presenta uno stretto range dinamico, permettendo di quantificare fino a 3-4 $\log _{10}$ di copie di CMV DNA. La Real-Time PCR (RT-PCR) grazie alla possibilità di quantizzare nella fase esponenziale dell'amplificazione, permette di determinare la quantità di DNA virale con un range dinamico superiore, senza richiedere una fase post-PCR per cui risulta minimo il rischio di contaminazione. Inoltre, la real-time PCR è una tecnologia con tempi di esecuzione rapidi, affidabile e riproducibile. Data la recente disponibilità commerciale di sistemi di identificazione e quantizzazione del DNA di CMV mediante RT-PCR, occorre stabilire come i risultati ottenuti con tale tecnica correlino con i dati ottenuti con le metodiche più largamente utilizzate come il test dell'antigene pp65 e l'endpoint PCR.

In questo studio sono stati confrontati il sistema commerciale end-point PCR COBAS AMPLICOR CMV Monitor (Roche, Branchburg, NJ, US), con il sistema RT-PCR, Q-CMV Real Time System, (Amplimedical, Buttigliera, To, I) per l'identificazione e quantizzazione del DNA di CMV. Sono stati studiati i leucociti del sangue periferico $(\mathrm{PBL})$ di pazienti sottoposti a trapianto di organo solido con infezione da CMV. È stata fatta un'analisi retrospettiva mediante RT-PCR di campioni provenienti da pazienti infetti da CMV e positivi con COBAS AMPLICOR e i dati di RTPCR sono stati correlati con quelli ottenuti mediante EP-PCR e con l'antigenemia.

\section{MATERIALI E METODI \\ Pazienti e campioni}

Lo studio è stato effettuato su 32 pazienti sottoposti a trapianto di fegato nel Centro di Trapianti di Fegato dell'Ospedale Molinette di Torino, nel periodo compreso tra gennaio e dicembre 2003, che avevano presentato una infezione da CMV entro i primi 6 mesi dall'intervento. L'infezione da CMV è stata monitorata con l'antigenemia per pp65 e il DNA virale con COBAS AMPLICOR su leucociti del sangue periferico. I campioni sono stati prelevati due volte la settimana per i primi tre mesi e ogni quindici giorni fino al $6^{\circ}$ mese di follow-up. Aliquote di 1 milione di PBL sono state conservate $\mathrm{a}-20^{\circ} \mathrm{C}$ per successive analisi.

\section{Definizione di infezione da CMV}

L'infezione da CMV è stata definita dalla presenza di DNA virale nei leucociti del sangue in assenza di manifestazioni cliniche (12). L'infezione primaria è stata osservata in tre riceventi sieronegativi il cui organo proveniva da un donatore sieropositivo. La reinfezione/riattivazione si è sviluppata in 29 pazienti sieropositivi riceventi l'organo da donatore sieropositivo/negativo. I pazienti con più di $20 \mathrm{PBL}$ positivi/200.000 cellule al test per l'antigene pp65 sono stati trattati con Ganciclovir (GCV) $(10 \mathrm{mg} / \mathrm{kg} / \mathrm{die})$ per 21 giorni oppure fino alla diminuzione del $90 \%$ DNA virale rispetto al livello misurato prima d'iniziare il trattamento. Durante il follow-up nessun paziente ha sviluppato sintomi legati all'infezione da CMV.

\section{Quantizzazione del DNA di CMV con PCR}

End-point PCR (EP-PCR). Per identificare e quantificare il DNA virale è stato usato il sistema COBAS AMPLICOR CMV Monitor che amplifica la regione UL54 del genoma di CMV (gene amino-terminale DNA Polimerasi) apportando alcune modifiche alla preparazione dei campioni, rappresentati da PBL. I PBL sono stati estratti e portati alla concentrazione finale di 2 milioni di cellule in $400 \mu 1$ di PBS; $50 \mu 1$ (corrispondenti a 250.000 cellule) sono stati caricati nella PCR. Lo standard interno QS è stato aggiunto ad ogni campione durante la fase di estrazione del DNA, come controllo di efficienza dell'estrazione e dell'amplificazione. Nella nostra esperienza il sistema è in grado di identificare fino a 100 copie di DNA di CMV su $10^{6} \mathrm{PBL}$ e presenta un range 
dinamico fino a $10^{5}$ copie $/ 10^{6} \mathrm{PBL}$. I risultati sono stati riportati come $\log _{10} / 500.000 \mathrm{PBL}$.

Real time PCR (RT-PCR). Le analisi con la realtime PCR sono state effettuate utilizzando il sistema commerciale TaqMan Q-CMV Real Time System (Amplimedical, Buttigliera, To, I) in formato multiplex, in grado di amplificare il gene UL123 (Immediatly Early 1, exon 4) di CMV ed il gene umano $\beta$-globina come controllo interno. Il DNA è stato estratto a partire dai PBL seguendo il protocollo QIAmp Blood mini-kit (Qiagen, $\mathrm{Mi}, \mathrm{I})$. Il DNA ottenuto da 50.000 leucociti $(5 \mu \mathrm{l})$ è stato usato come input per la successiva amplificazione. Il sistema prevede l'uso di un probe specifico per il target virale di tipo Minor Groove Binder (MGB) marcato con il fluorocromo FAM mentre una sonda marcata con un altro fluorocromo, VIC, è stata usata per identificare il gene umano. Il DNA virale è stato amplificato con lo strumento ABI PRISM 7700 Sequence Detection System (Perkin-Elmer Biosystem, Fosters City, Calif.) in una mix finale di reazione di $50 \mu 1$. Le condizioni di amplificazione sono state le seguenti: $50^{\circ} \mathrm{C}$ per $2 \mathrm{~min}, 95^{\circ} \mathrm{C}$ per $10 \mathrm{~min}$, e 45 cicli di $95^{\circ} \mathrm{C}$ per $15 \mathrm{sec}$ e $60^{\circ} \mathrm{C}$ per $1 \mathrm{~min}$. Il sistema lavora basandosi su di una curva standard di quantizzazione esterna costruita con diluizioni di un plasmide contenente il gene UL123 che vanno da $10^{2}$ a $10^{5}$ copie/reazione. I risultati sono stati riportati come $\log _{10}$ copie/500.000 PBLs.

Sensibilità e specificità delle tecniche PCR. Il DNA purificato dal ceppo di riferimento CMV AD169 (1,5 x10 copie di genoma virale/ $\mu 1$, Experteam, I) è stato usato per testare la sensibilità di entrambe le metodiche di amplificazione. Diluizioni seriali di DNA virale sono state preparate ed utilizzate alle seguenti concentrazioni: $1000,100,10$ e 1 copie/reazione. Per valutare la riproducibilità della RT-PCR sono stati confrontati i valori ottenuti nel medesimo esperimento su campioni ripetuti e in diversi saggi. La specificità dei due sistemi di PCR è stata valutata testando ceppi di altri herpesvirus (Herpes Simplex tipo 1 e 2, Varicella-Zoster virus ed Epstein Barr virus).

\section{Ricerca dell'antigene pp65 di CMV}

Aliquote di 200.000 leucociti di sangue periferico sono usati per allestire preparati mediante citocentrifugazione. I leucociti sono stati fissati in formaldeide al $5 \%$ e testati con un pool di anticorpi monoclonali specifici per l'antigene pp65 dei CMV (1C3+AYM-1, Argene, Biosoft, Varilhes, F), quindi incubati con anticorpo secon-

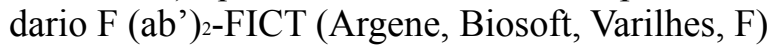
ed infine esaminati in microscopia a fluorescenza. Le cellule positive per pp65 sono state contate e riferite a 200.000 leucociti.

\section{Analisi statistica}

Per tutti i dati analizzati è stata calcolata la mediana e la media \pm deviazione standard (media \pm DS). Il test $T$ Student è stato usato per confrontare le differenze tra le categorie (significatività per valori di $p<0,05)$. La correlazione tra categorie è stata valutata mediante regressione lineare e i dati a tal scopo sono stati trasformati in $\log _{10}$.

\section{RISULTATI}

Sono stati studiati 158 campioni positivi per il DNA di CMV con COBAS AMPLICOR e provenienti da 32 pazienti che avevano sviluppato una infezione asintomatica da CMV durante $\mathrm{i}$ primi sei mesi dopo il trapianto. Venti soggetti che presentavano livelli di antigenemia maggiori di $20 \mathrm{PBL}$ positivi/200.000 cellule, sono stati sottoposti a terapia con GCV, mentre 12 pazienti non sono stati trattati. I PBL positivi per il virus sono stati retrospettivamente analizzati in RT-PCR.

Confronto tra real-time PCR, end-point PCR e antigenemia. RT-PCR ha misurato da 1,3 a 5,9 $\log _{10}$ copie di DNA di CMV su 500.000 PBLs (corrispondenti a 20-860.000 copie) in 155 campioni dei 158 risultati positivi con COBAS AMPLICOR MONITOR (copie di genoma virale comprese tra 1,8 e $4,5 \log _{10}$, corrispondenti a 70-31.000 copie su 500.000 PBL). In ciascun saggio di RT-PCR è stato amplificato con successo il gene della $\beta$-globina. La concordanza tra le tecniche di PCR è stata del $98 \%$ con $155 / 158$ campioni positivi in entrambe le metodiche. Tre campioni positivi con COBAS AMPLICOR MONITOR e con il test per la ricerca dell'antigene pp65 (1-2 cellule/200.000 e i valori di CMV DNA compresi tra 2 e $3 \log$ ) sono risultati negativi con RT-PCR.

La correlazione tra le due tecniche di PCR ed con il test dell'antigene pp65 è stata studiata in 126 campioni che presentavano una o più cellule positive per pp65. Una buona correlazione è stata trovata tra il test dell'antigene pp65 e la RT-PCR $\quad(r=0,691)$ e il sistema COBAS AMPLICOR MONITOR $\quad(r=0,722)$. Considerando tutti i risultati indipendentemente dai valori ottenuti con l'antigene pp65, è stata osservata una significativa correlazione tra le due metodiche di PCR ( $r=0,761$, figura I). In rapporto ai livelli di pp65, il grado di correlazione tra le due metodiche è risultato simile per valori sia superiori che inferiori a 50 cellule positive per pp65 $(r=0,702$ e $r=0,76$, rispettivamente).

Nella tabella 1 sono riportati i valori mediani di pp65, di CMV DNA con l'end-point PCR e la 
real-time PCR nei pazienti trattati con anti-virale e in quelli non trattati. Il valore mediano di CMV DNA ottenuto con la RT-PCR nei pazienti trattati con GCV era di $3,8 \log _{10} / 500.000 \mathrm{PBL}$ (media \pm DS: $3,5 \pm 1$ ) mentre il livello di DNA era significativamente più basso in quelli non trattati: 2,9 (media \pm DS: $2,8 \pm 0,8$ ) $\log _{10} / 500.000 \mathrm{PBL}$ $(\mathrm{p}<0,0001)$. Il numero delle copie ottenuto mediante COBAS AMPLICOR era 3,9 $(3,9 \pm 0,2)$ nei pazienti sottoposti a terapia e $3,1(3,1 \pm 0,3)$ $\log _{10} / 500.000$ PBL $(\mathrm{p}<0,0001)$ in quelli non trattati. Perciò sia la EP-PCR sia la RT-PCR hanno dato risultati concordanti con quelli ottenuti con il test dell'antigene pp65 che aveva valori molto più alti nei riceventi sottoposti a terapia $[98$ (media+DS: $257 \pm 320$ )] rispetto a quelli non trat-

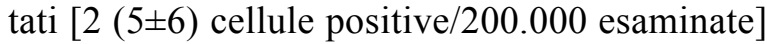
$(\mathrm{p}=0,001)$.

I valori del test per l'antigene pp65 sono stati utilizzati per suddividere i campioni in sei categorie cliniche corrispondenti a diversi livelli di infezione: il gruppo 1 comprendente i campioni negativi per pp65; il gruppo 2 costituito dai campioni con livelli di antigenemia compresi tra $1 \mathrm{e}$ 10 cellule, il gruppo 3 con livelli compresi tra 11 e 20; il gruppo 4 con livelli di pp65 tra 21 e 50; il gruppo 5 con livelli compresi tra 51 e 100 ed il gruppo 6 per campioni con più di 100 cellule positive per pp65. In ciascuna categoria sono state calcolate le mediane dei livelli di DNA virale con entrambe le metodiche di PCR, al fine di capire come le due tecniche discriminino tra pazienti con differenti livelli d'infezione. Come riportato nella tabella 2, quando il test dell'antigene pp65 era negativo, il valore mediano di CMV DNA ottenuto con real-time PCR era 2,6 $\log _{10}$ copie/500.000 PBL (media \pm DS: $2,8 \pm 0,8$ ) molto simile a quello ottenuto con COBAS AMPLICOR (2,8 logs). Nei gruppi 2, 3, 4, 5 e 6 il livello di DNA di CMV ottenuto con RT-PCR è cresciuto progressivamente da 3,0 a $3,6,4,0$, 4,2 fino a $4,8 \operatorname{logs}$, rispettivamente, mentre con il sistema COBAS AMPLICOR la progressione buona dal gruppo 2 al 3, da 2,9 a 3,8 logs, ma meno evidente negli altri gruppi: 3,7- 3,9 e 4,0 logs. I valori della real-time e della end-point PCR erano comunque significativamente più alti nei gruppi 3, 4, 5 e 6, categorie in cui i campioni presentavano un numero di cellule positive al test dell'antigene pp65 maggiore di 10, a differenza delle categorie 1 (meno di 10 cellule positive) e 2 (antigenemia negativa, $p<0,00001$ ). Per i campioni con più di 20 cellule positive per pp65 (gruppi 4, 5 e 6), valore per l'inizio della terapia precoce, i valori di DNA ottenuti con RTPCR erano significativamente maggiori di quelli dei gruppi con meno di 20 cellule positive (gruppo 3) $(\mathrm{p}=0,01)$ mentre con COBAS AMPLICOR non sono state osservate significative differenze $(\mathrm{p}=0,2)$.

\section{Efficienza, riproducibilità, sensibilità e speci- ficità della Real-time PCR.}

La riproducibilità del test di RT-PCR è stata determinata utilizzando diluizioni da $10^{2}$ a $10^{5}$ copie/reazione di DNA di CMV del ceppo di riferimento AD169 (tabella 3).

Per determinare le variazioni intra-assay, sono state valutate in triplicato nello stesso esperimento 4 diluizioni di DNA virale. I valori medi del coefficiente di correlazione (CV\%) erano $1,9 \%$, $0,5 \%, 0,6 \%$ e $0,9 \%$ per i punti standard $10^{2}, 10^{3}$, $10^{4}, 10^{5}$ copie/reazione, rispettivamente. La variabilità inter-assay è stata valutata testando diluizioni standard del ceppo AD169 in duplicato in 6 esperimenti condotti in sedute differenti. I CV ottenuti sono stati i seguenti: $1,8 \%$ alla concentrazione di $10^{2}, 1,0 \%$ per $10^{3}, 0,7 \%$ per $10^{4} \mathrm{e}$ $1,7 \%$ per la concentrazione $10^{5}$ copie/reazione. La sensibilità delle due metodiche di amplificazione è stata valutata utilizzando diluizioni seriali di AD169 (tabella 4). Per un numero di copie/reazione di 1000 e 100 la sensibilità ottenuta era del $100 \%$ in entrambi i sistemi; quando il numero di copie/reazione era 10 era sempre del $100 \%$ per la RT- PCR ma scendeva al $28,5 \%$ per COBAS AMPLICOR. Con un input iniziale di 1 copia di CMV DNA la sensibilità è stata del 57\% con RT-PCR mentre COBAS AMPLICOR era negativo.

\section{Discussione}

Nella maggior parte dei pazienti trapiantati di organo solido, CMV è responsabile di importanti infezioni che possono associarsi al rigetto dell'organo e ad altre infezioni batteriche e fungine. La terapia precoce dell'infezione da CMV è la strategia più efficace per controllare la riattivazione virale $(18,28)$. Per identificare gli stadi iniziali dell'infezione e stabilire il trattamento di essa è necessario disporre di tecniche altamente sensibili. Il test dell'antigene pp65 e la quantizzazione del DNA di CMV sono i metodi migliori per identificare precocemente i pazienti infetti e tra essi quelli che presentano elevato rischio di evoluzione dell'infezione $(1,3,8,13,19,26,27)$. Il test dell'antigene pp65 è considerato il test di riferimento per la diagnosi precoce dell'infezione da CMV ma presenta alcuni limiti che ne diminuiscono la sensibilità e la specificità. La necessità di processare immediatamente $\mathrm{i}$ campioni per ottenere risultati qualitativamente validi e l'utilizzo di un numero di leucociti che non è sempre disponibile per i pazienti fortemente leucopenici, sono tra i maggiori svantaggi del test che pertan- 
to è difficilmente standardizzabile e poco adatto per la routine in laboratori collegati a grossi centri di trapianti $(15,28)$.

L'identificazione del DNA di CMV mediante PCR permette di determinare l'infezione ancora più precocemente del test dell'antigene pp65 (3, $30,31)$. Con la PCR quantitativa è possibile determinare livelli di DNA predittivi dell'evoluzione dell'infezione e identificare i pazienti ad alto rischio che richiedono la terapia precoce. Elevati livelli di DNA di CMV nei primi mesi dopo il trapianto, sono infatti correlati all'aumento del rischio di progressione dell'infezione (7, $10,24,25,26)$. Inoltre, diversi studi evidenziano come la quantizzazione di CMV DNA possa essere utilizzata per valutare la risposta agli antivirali $(15,16,17,18,26,27,28)$.

La caratteristica principale della RT-PCR è l'assenza dello step di post-amplificazione; la quantizzazione dei prodotti ottenuti è realizzata analizzando la fase logaritmica della curva di amplificazione. L'incremento del genoma amplificato è controllato durante ogni ciclo ed il ciclo soglia è definito per ciascun campione come il punto della fase di crescita esponenziale in cui si ha il primo segnale di fluorescenza statisticamente significativo al di sopra del segnale di fondo. Nella RT-PCR la quantizzazione non è influenzata da nessun reagente che può diventare limitante nella fase di plateau ed è caratterizzata da elevata riproducibilità, come attestato dal basso coefficiente di variazione da noi ottenuto sia intra che inter-assay (entrambi $<2 \%$ ).

Nel nostro studio, abbiamo riscontrato una buona concordanza $(98 \%)$ tra i risultati ottenuti con le due tecniche di PCR anche se con la RT-PCR tre campioni sono risultati negativi e ciò potrebbe dipendere dalla minore quantità di DNA utilizzato come input iniziale: nella RT-PCR l'input di reazione corrisponde a 50.000 cellule mentre nella EP-PCR a 250.000. Se consideriamo i valori di sensibilità ottenuti con le due differenti procedure di PCR con diluizioni seriali del ceppo di riferimento $\mathrm{AD} 169$, possiamo invece riportare una sensibilità per la real-time PCR maggiore rispetto alla EP-PCR.

In accordo con quanto riportato da altri studi (5, 9, 10, 14, 20, 21, 29), la RT-PCR dimostra una buona correlazione con il test dell'antigene pp65. Sia con il test dell'antigene pp65 sia con il sistema commerciale Taqman è stato possibile discriminare differenti livelli d'infezione da CMV. Sono stati definiti 6 livelli di antigenemia: 0, 1$10,11-20,21-50,51-100$ e $>100$ cellule pp65 positive a cui corrispondevano i seguenti valori mediani della carica virale: 2.6, 3.0, 3.6, 4.0, 4.2, e $4.8 \log _{10}$ copie/500.000 PBL. Nei pazienti con più di 20 cellule pp65 positive considerato dal nostro Centro come livello per iniziare la terapia preventiva, è stato osservato un significativo aumento della quantità di DNA virale, rispetto a quello dei pazienti con meno di 20 cellule positive per pp65 o con antigenemia negativa. I valori ottenuti per le stesse categorie con COBAS AMPLICOR erano caratterizzati da un più lento progredire dell'aumento della carica virale: rispettivamente $2.8,2.9,3.8,3.7,3.9$, e $4.0 \log _{10}$.

L'introduzione della real-time PCR nello studio della dinamica dell'infezione da CMV porta importanti vantaggi di cui i principali a nostro avviso sono i seguenti: 1) una più affidabile quantizzazione del DNA virale, in particolare per quantità moderate e alte di genoma virale con la possibilità di ottenere informazioni più precise sulla cinetica virale per valutare meglio come evolve l'infezione e controllare la risposta antivirale; 2) un tempo di risultati molto rapido dovuto alla rapida amplificazione e l'analisi in tempo reale del prodotto di amplificazione: circa 3 ore complessivamente (1 ora per l'estrazione del DNA dal campione di partenza e 2 ore per la reazione di PCR), contro le 6 ore impiegate con COBAS AMPLICOR MONITOR; 3) un'alta riproducibilità inter- ed intra-assay $(\mathrm{CV}<2 \%) \mathrm{e}$ una migliore sensibilità e specificità rispetto $\mathrm{al}$ sistema EP-PCR; 4) il sistema RT-PCR in assetto multiplex permette di identificare simultaneamente target e un gene utilizzato come controllo interno per valutare la competenza del DNA estratto. La RT-PCR può essere completamente automatizzata mediante piattaforme in cui l'intero processo dall'estrazione all'amplificazione e rivelazione dei risultati viene eseguito in automatico, permettendo l'analisi contemporanea di un gran numero di campioni.

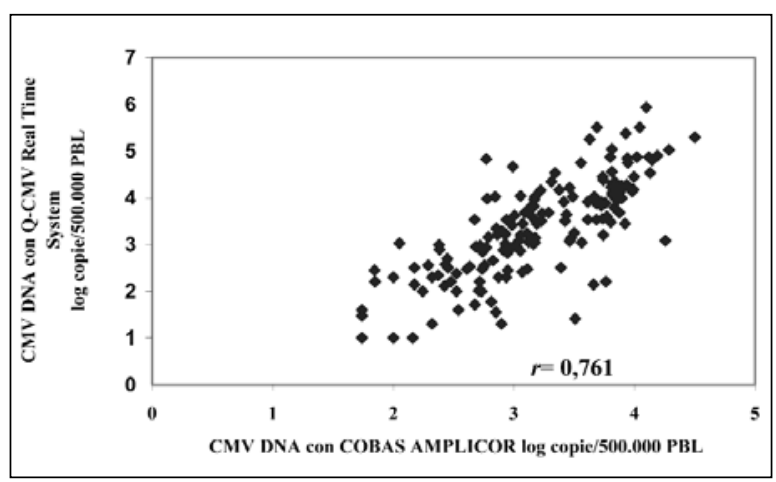

Figura I. Confronto dei valori di CMV DNA ottenuti con la tecnica COBAS AMPLICOR MONITOR e Q-CMV Real Time System nei campioni analizzati 
Tabella I. Confronto tra i valori ottenuti nei tre differenti test (RT-PCR, COBAS AMPLICOR MONITOR e test dell'antigene pP65) in pazienti sottoposti a terapia precoce e in quelli non trattati.

\begin{tabular}{|c|c|c|c|}
\hline & $\begin{array}{l}\text { Test dell'antigene pp65 } \\
\text { cellule positive/200.000PBL }\end{array}$ & $\begin{array}{l}\text { COBAS AMPLICOR } \\
\log _{10} \text { copie/500.000 PBL }\end{array}$ & $\begin{array}{c}\text { Q-CMV Real-Time } \\
\text { System } \\
\log _{10} \text { copie/500.000 PBL }\end{array}$ \\
\hline & \multicolumn{3}{|c|}{ Valore mediano (media $\pm D S$ ) } \\
\hline $\begin{array}{l}\text { Pazienti trattati \# } \\
(n=20)\end{array}$ & $\begin{array}{c}98^{*} \\
(257 \pm 320)\end{array}$ & $\begin{array}{c}3,9 \text { *** } \\
(3,9 \pm 0,2)\end{array}$ & $\begin{array}{c}3,8^{\circ} \\
(3,5 \pm 1)\end{array}$ \\
\hline $\begin{array}{l}\text { Pazienti non trattati } \\
(n=12)\end{array}$ & $\begin{array}{c}2^{*} \\
(5 \pm 6)\end{array}$ & $\begin{array}{c}3,1 * * k \\
(3, I \pm 0,3)\end{array}$ & $\begin{array}{c}2,9^{\circ} \\
(2,8 \pm 0,8)\end{array}$ \\
\hline
\end{tabular}

\# Livello massimo di DNA virale di CMV prima del trattamento $(10 \mathrm{mg} / \mathrm{kg} /$ die per 21 giorni).

* $T$ test: $\mathrm{p}=0,01$

** T test: $p<0,0001$

- $T$ test : $p<0,0001$

Tabella 2. Correlazione tra differenti gruppi di valori di pp65 e DNA di CMV con i sistemi end-point PCR e real-time PCR.

\begin{tabular}{|c|c|c|c|}
\hline & \multirow[t]{2}{*}{ Livelli dell'antigene pp65 } & \multicolumn{2}{|c|}{ CMV DNA } \\
\hline & & Q-CMV Real-time System & COBAS AMPLICOR \\
\hline Gruppi* & Numero di cellule positive/200.000 PBL & $\begin{array}{r}\log _{10} \text { copie/ } \\
\text { Valore } \\
\text { (med }\end{array}$ & BL \\
\hline 1 & 0 & $\begin{array}{c}2,6 \\
(2,8 \pm 0,8)\end{array}$ & $\begin{array}{c}2,8 \\
(2,8 \pm 0,5)\end{array}$ \\
\hline 2 & $1-10$ & $\begin{array}{c}3,0 \\
(2,9 \pm 1)\end{array}$ & $\begin{array}{c}2,9 \\
(2,9 \pm 0,5)\end{array}$ \\
\hline 3 & $11-20$ & $\begin{array}{c}3,6 \\
(3,6 \pm 0,7)\end{array}$ & $\begin{array}{c}3,8 \\
(3,7 \pm 0,3)\end{array}$ \\
\hline 4 & $21-50$ & $\begin{array}{c}4,0 \\
(4,2 \pm 0,6)\end{array}$ & $\begin{array}{c}3,7 \\
(3,6 \pm 0,3)\end{array}$ \\
\hline 5 & $51-100$ & $\begin{array}{c}4,2 \\
(4, I \pm 0,6)\end{array}$ & $\begin{array}{c}3,9 \\
(3,8 \pm 0,2)\end{array}$ \\
\hline 6 & $>100$ & $\begin{array}{c}4,8 \\
(4,7 \pm 0,7)\end{array}$ & $\begin{array}{c}4,0 \\
(3,9 \pm 0,5)\end{array}$ \\
\hline
\end{tabular}

* Definiti in base al numero di cellule positive per il test dell'antigene pp65, come riportato nella colonna affianco. Vedi testo per dettagli.

Tabella 3. Riproducibilità di Q-CMV Real Time System determinata esaminando diluizioni standard (da $10^{2}$ a $10^{5}$ copie/reazione) di DNA di CMV del ceppo di riferimento ADI69.

\begin{tabular}{lcccc}
\hline & \multicolumn{5}{c}{ CMV DNA copie/reazione } \\
\hline & $10^{2}$ & $10^{3}$ & $10^{4}$ & $10^{5}$ \\
CV intra-assay* (\%) & 1,9 & 0,5 & 0,6 & 0,9 \\
CV inter-assay** (\%) & 1,8 & 1,0 & 0,7 & 1,7 \\
\hline *Media dei campioni analizzati in triplicato nel medesimo esperimento (4 prove) \\
**Media di 6 esperimenti indipendenti eseguiti in duplicato in differenti giorni
\end{tabular}

Tabella 4. Confronto della sensibilità delle tecniche end-point e real-time PCR.

\begin{tabular}{ccccccc}
\hline $\begin{array}{c}\text { CMV DNA } \\
\text { Quantità iniziale* }\end{array}$ & \multicolumn{3}{c}{ COBAS AMPLICOR } & \multicolumn{3}{c}{ Q-CMV Real-Time System } \\
\hline Copie/ reazione & Prove effettuate & Esito positivo & Percentuale di & $\begin{array}{c}\text { Prove } \\
\text { effettuate }\end{array}$ & Esito positivo & $\begin{array}{c}\text { Percentuale di } \\
\text { positività (\%) }\end{array}$ \\
1 & 7 & 0 & - & 7 & 4 & 57 \\
10 & 7 & 2 & 28,5 & 7 & 7 & 100 \\
100 & 4 & 4 & 100 & 4 & 4 & 100 \\
1000 & 4 & 4 & 100 & 4 & 4 & 100 \\
\hline
\end{tabular}

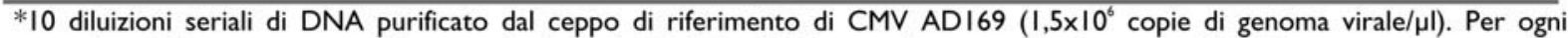
procedura PCR sono state amplificate in duplicato I, 10, 100 e 1000 copie di genoma di riferimento ADI69. 


\section{BIBLIOGRAFIA}

1. Aitken CW, Barrett-Muir C, Millar, Templeton K, et al. Use of molecular assays in diagnosis and monitoring of cytomegalovirus disease following renal transplantation. J Clin Microbiol 1999; 37: 2804-7.

2. Barber L, Egan JJ, Lomax J, et al. A prospective study of a quantitative PCR ELISA assay for the diagnosis of CMV pneumonia in lung and heart-transplant recipients. J Heart Lung Transplant 2000; 19: 771-80.

3. Boeckh M, Boivin G. Quantitation of cytomegalovirus: methodologic aspects and clinical applications. Clin Microbiol Rev 1998; 11: 533-54.

4. Camargo LF, Uip DE, Simpson AA, et al. Comparison between antigenemia and a quantitative-competitive polymerase chain reaction for the diagnosis of cytomegalovirus infection after heart transplantation. Transplantation; 71: 412-7.

5. Gault E, Michel Y, Dehee A, Belabani C, Nicolas JC, Garbarg-Chenon A. Quantification of human cytomegalovirus DNA by real-time PCR. J Clin Microbiol 2001; 39: 772-5.

6. Gerna G, Furione M, Baldanti F, Sarasini A. Comparative quantitation of human cytomegalovirus DNA in blood leukocytes and plasma of transplant and AIDS patients. J Clin Microbiol 1994; 32: 270917.

7. Ghisetti V, Barbui A, Franchello A, et al. Quantitation of cytomegalovirus DNA by the polymerase chain reaction as a predictor of disease in solid organ transplantation. J Med Virol 2004; 73: 223-9.

8. Griffiths PD, Cope AV, Hassan-Walker AF, Emery VC. Diagnostic approaches to cytomegalovirus infection in bone marrow and organ transplantation. Transplant Infect Dis 1999; 1: 179-86.

9. Griscelli F, Barrois M, Chauvin S, Lastere S, Bellet D, Bourhis JH. Quantification of human cytomegalovirus DNA in bone marrow transplant recipients by real-time PCR. J Clin Microbiol 2001; 39: 4362-9.

10. Guiver M, Fox AJ, Mutton K, Mogulkoc N, Egan J. Evaluation of CMV viral load using TaqMan CMV quantitative PCR and comparison with CMV antigenemia in heart and lung transplant recipients. Transplantation 2001; 71: 1609-15.

11. Haijing L, Dummer JS, Estes WR, Meng S, Wright PF, Tang WJ. Measurement of human cytomegalovirus loads by quantitative Real-time PCR for monitoring clinical intervention in transplant recipients. J Clin Microbiol 2003; 41: 187-91.

12. Ljungman P, Griffiths P, Paya C. Definitions of cytomegalovirus infection and disease in transplant recipients. Clin Infect Dis 2002; 34: 1094-7.

13. Mattes FM, Hainsworth EG, Hassan-Walker AF, et al. Kinetics of cytomegalovirus load decrease in solidorgan transplant recipients after preemptive therapy with valganciclovir. J Infect Dis 2005; 191: 89-92.

14. Mengelle C, Pasquier C, Rostaing L, et al. Quantitation of human cytomegalovirus in recipients of solid organ transplants by Real-time PCR and pp65 antigenemia. J Med Virol 2003; 69: 225-31.

15. Monte PD, Lazzarotto T, Ripalti A, Landini MP. Human cytomegalovirus infection: a complex diagnostic problem in which molecular biology has induced a rapid evolution. Intervirology 1996; 39: 193-203.
16. Paya CV, Sia IG, Wilson JA, Groettum CM, Espy MJ, Smith TF. Cytomegalovirus (CMV) DNA load predicts relapsing CMV infection after solid organ transplantation. J Infect Dis 2000a; 181: 717-20.

17. Paya CV. Prevention of cytomegalovirus disease in recipients of solid-organ transplants. Clin Infect Dis 2001b; 32: 596-603.

18. Paya CV, Wilson JA, Espy MJ et al. Preemptive use of oral ganciclovir to prevent cytomegalovirus infection in liver transplant patients: a randomized, placebocontrolled trial. J Infect Dis 2002c; 185: 854-60.

19. Preiksaitis JK, Brennan DC, Fishman J, Allen U. Canadian society of transplantation consensus workshop on cytomegalovirus management in solid organ transplantation final report. Am J Transplant 2005; 5: 218-27.

20. Pang XL, Chui L, Fenton J, LeBlanc B, Preiksaitis JK. Comparison of LightCycler-based PCR, COBAS amplicor CMV monitor, and pp65 antigenemia assays for quantitative measurement of cytomegalovirus viral load in peripheral blood specimens from patients after solid organ transplantation. J Clin Microbiol 2003; 41: 3167-74.

21. Piiparinen H, Hockerstedt K, Gronhagen-Riska C, Lautenschlager I. Comparison of two quantitative CMV PCR tests, Cobas Amplicor CMV Monitor and TaqMan assay, and pp65-antigenemia assay in the determination of viral loads from peripheral blood of organ transplant patients. J Clin Virol 2004; 30: 25866.

22. Razonable RR, Brown RA, Wilson J, et al. The clinical use of various blood compartments for cytomegalovirus (CMV) DNA quantitation in transplant recipients with $\mathrm{CMV}$ disease. Transplantation 2002a; 73: 968-73.

23. Razonable RR, Paya CV, Smith TF. Role of the laboratory in diagnosis and management of cytomegalovirus infection in hematopoietic stem cell and solid-organ transplant recipients. J Clin Microbiol 2002b; 40: 746-752.

24. Roberts TC, Brennan DC, Buller RS, et al. Quantitative polymerase chain reaction to predict occurrence of symptomatic cytomegalovirus infection and assess response to ganciclovir therapy in renal transplant recipients. J Infect Dis 1998; 178: 626-35.

25. Sanchez JL, Kruger RM, Paranjothi S, et al. Relationship of cytomegalovirus viral load in blood to pneumonitis in lung transplant recipients. Transplantation 2001; 72: 733-5.

26. Sia IG, Wilson JA, Groettum CM, Espy MJ, Smith TF, Paya CV. Cytomegalovirus (CMV) DNA load predicts relapsing CMV infection after solid organ transplantation. J Infect Dis 2000a; 181: 717-20.

27. Sia IG, Wilson JA, Espy MJ, Paya CV, Smith TF. Evaluation of the COBAS AMPLICOR CMV MONITOR test for detection of viral DNA in specimens taken from patients after liver transplantation. J Clin Microbiol 2000b; 38: 600-6.

28. Sia IG, Patel R. New strategies for prevention and therapy of cytomegalovirus infection and disease in solid-organ transplant recipients. Clin Microbiol Rev 2000c; 13: 83-121.

29. Tanaka N, Kimura H, Iida K, et al. Quantitative analysis of cytomegalovirus load using a real-time PCR assay. J Med Virol 2000; 60: 455-62.

30. Tong CY, Cuevas LE, Williams H, Bakran A. Prediction and diagnosis of cytomegalovirus disease 
in renal transplant recipients using qualitative and quantitative polymerase chain reaction. Transplantation 2000; 69: 985-91.

31. Vanpoucke H, Van Vlem B, Vanholder R, Van Renterghem L. Significance of qualitative polymerase chain reaction combined with quantitation of viral load in the diagnosis and follow-up of cytomegalovirus infection after solid-organ transplantation. Intervirology 1999; 42: 398-404.

Tiziano Allice

Laboratorio di Microbiologia

Ospedale Molinette

Corso Bramante 88/90 - 10126 Torino

E-mail: tizall@yahoo.it 